\title{
Attainment of Favorable Microstructure for Residual Stress Reduction Through High-Temperature Heat Treatment on Additive Manufactured Inconel 718 Alloy
}

\author{
Vijayakumar Praveen Kumar \\ Vellore Institute of Technology \\ Alfred Vinoth Jebaraj ( $\sim$ vjebaraj@gmail.com ) \\ Vellore Institute of Technology
}

\section{Research Article}

Keywords: Additive manufacturing, Inconel 718, Residual stress, Heat treatment, and Hardness

Posted Date: January 25th, 2022

DOI: https://doi.org/10.21203/rs.3.rs-1151578/v1

License: (a) (1) This work is licensed under a Creative Commons Attribution 4.0 International License.

Read Full License 
Attainment of favorable microstructure for residual stress reduction through hightemperature heat treatment on additive manufactured Inconel 718 alloy

\author{
Vijayakumar Praveen Kumar ${ }^{\text {a }}$, Alfred Vinoth Jebaraj ${ }^{a^{*}}$
}

${ }^{\text {a }}$ School of Mechanical Engineering, Vellore Institute of Technology, Vellore-632014, India.

1. Vijayakumar Praveen Kumar (First Author)

School of Mechanical Engineering,

Vellore Institute of Technology,

Vellore-632014, India.

e-mail: praveenkumar.v@vit.ac.in

2. Alfred Vinoth Jebaraj (Corresponding Author)

School of Mechanical Engineering,

Vellore Institute of Technology,

Vellore-632014, India.

e-mail: vjebaraj@gmail.com 


\section{Attainment of favorable microstructure for residual stress reduction through high- temperature heat treatment on additive manufactured Inconel 718 alloy}

\section{Abstract}

The mitigation of residual stress in additive manufactured metal parts through postheat treatment helps to enhance life during service. The present work aims to investigate the effect of the high-temperature heat treatment at $1065^{\circ} \mathrm{C}$ on microstructural changes, residual stress patterns, and hardness of Inconel 718 metal blocks fabricated through the Laser powder bed fusion (L-PBF) process. The non-destructive X-ray diffraction technique known as $\cos \alpha$ method was used to measure the surface residual stress by capturing the Debye ring. It was found that the existence of columnar dendrites with laves phases in the interdendritic region along the building direction was dissolved after heat treatment. The resultant microstructure showed homogeneous equiaxed grains with the formation of annealing twins along with strengthening phases $\left(\gamma^{\prime}\right.$ and $\left.\gamma^{\prime \prime}\right)$ and tiny metal carbides on the grain boundaries. Further, the residual stress magnitude in the as-built sample was found to be $77 \%$ higher on the corners compared to the center region of the top surface. The average value of residual stress on the top surface was found to be $35.5 \%$ lesser than the lateral side surface of the sample. It was observed that the distribution of residual stress is not uniform in as-built condition. The heattreated sample showed uniform distribution of compressive residual stresses in all the locations. This phenomenon happened due to the increase in diffusion of atoms present in the high-stress regions migrated to low-stress regions till attain their equilibrium condition. During this action, the stresses present in the grain interiors were altered considerably and resulted in complete recrystallization with the precipitation of more strengthening phases and annealing twins. The high-temperature post-heat treatment also affects the hardness leads to $23.03 \%$ increase in average microhardness mainly induced resistance to dislocation motion by precipitation of strengthening phases in the $\gamma$ matrix. 
Keywords: Additive manufacturing, Inconel 718, Residual stress, Heat treatment, and Hardness

\section{Introduction}

Inconel 718 (IN718) is an age-hardening nickel (Ni) based superalloy most widely used at high-temperature applications like a nuclear reactor, turbochargers, and aircraft engines on account of its high strength, good weldability, good oxidation, creep resistance, and high mechanical stability at elevated temperatures up to $\sim 650^{\circ} \mathrm{C}[1-3]$. The IN718 alloy consists of a primary austenite $\gamma(\mathrm{Ni}-\mathrm{Cr}-\mathrm{Fe})$ matrix with an FCC crystal structure. The austenite phase is strengthened by precipitating $\gamma^{\prime}(\mathrm{Ni}(\mathrm{Al}, \mathrm{Ti}))$ and $\gamma^{\prime \prime}\left(\mathrm{Ni}_{3} \mathrm{Nb}\right)$ phases. However, it also forms some harmful intermetallic phases at the time of processing such as $\delta\left(\mathrm{Ni}_{3} \mathrm{Nb}\right)$ with orthorhombic $\mathrm{DO}_{\mathrm{a}}$ structure and laves $(\mathrm{Ni}, \mathrm{Fe}, \mathrm{Cr})_{2}(\mathrm{Nb}, \mathrm{Mo}, \mathrm{Ti})$ phases with a hexagonal crystal structure due to more segregation of $\mathrm{Nb}$ and Mo elements [4-7]. The desired properties of the alloy can be restored by eliminating the intermetallic phases and increasing the presence of strengthening phases [8].

The metal additive manufacturing (AM) process showed advantages in fabricating highly complex near-net-shape parts by melting the metal powders and stacking the layer one above the other. The Laser-based powder bed fusion (L-PBF) is a widely used technology among other metal AM processes in the industrial sector. However, L-PBF noticeably forms high anisotropic residual stresses when the fabricated component reached its equilibrium state and resulted in geometric distortion as well as reduction in fatigue life [9]. Mercelis et al. [10] explain the residual stress formation mechanism in the L-PBF process with the help of thermal gradient mechanism (TGM) and cool-down mechanism (CDM). At the time of heating, the melt pool try to expand outwards and the expansion was restricted by surrounding unmelted powder particles and previously fabricated layers leads to compressive residual stress. At the time of cooling, the expanded material try to 
shrink inward till it reaches their equilibrium condition, and the contraction was restricted by previously fabricated layers and surrounding material resulted in tensile residual stress. As a result, the final layers and the outer surface ended up with tensile residual stress in as-built samples [11]. In general, the L-PBF process experiences a high thermal gradient due to rapid cooling at the rate of $10^{3-} 10^{6} \mathrm{~K} / \mathrm{sec}[12]$.

The higher solidification rate and thermal gradient resulted in fine columnar dendritic microstructure. The dendritic structure is formed with high dislocation density by crossing various melt pool boundaries lead to more dislocations [13]. The residual stresses are stored in the form of elastic strain energy caused by high dislocations [14, 15]. The accumulation of localized residual stresses induces cracks initially at the melt pool boundaries in the as-built In718 microstructure [13]. The residual stresses distribution varies within the layer and between the layers due to its anisotropy in microstructure [9, 12, 16-18]. The anisotropy in microstructure and residual stress can be eliminated by the heat treatment process $[19,20]$.

The residual stress developed in the L-PBF process is a common cause of catastrophic failures. It includes geometric distortion, cracking, delamination, warpage, detaching parts from the build platform $[10,21]$. Also, affect the mechanical properties during cyclic loading [22]. The residual stress buildup can be controlled by preheating the build platform causes a slow cooling rate and thereby reducing the thermal gradient [23]. In addition, defining the optimum process parameters control the residual stress magnitude during fabrication. The major parameters that alter the residual stress formation are scan strategy, laser power, scan speed, hatch spacing, layer thickness, and built orientation [10, 21, and 23]. The above mentioned parameters control the volumetric energy density of the laser power source. Mirkoohi et al. [24] found that the magnitude of residual stress in the IN 718 sample is $180 \mathrm{MPa}$ in the build direction and $48 \mathrm{MPa}$ in the scanning direction. $\mathrm{Lu}$ 
et al. [22] reported the fabrication of IN718 with an island scanning strategy of $2 \times 2 \mathrm{~mm}$ island size ended up with the least residual stress magnitude of 110MPa. Mugwagwa et al. [25] reported that the higher laser beam power of $180 \mathrm{~W}$ possesses the highest residual stress magnitude of 221Mpa. Ahmad et al. [26] found that the IN 718 sample fabricated with the layer thickness of $30 \mu \mathrm{m}$ recorded a residual stress magnitude of 560MPa. Yi et al. [27] found that the higher energy density would increase the residual stress magnitude and result in more distortions. Moreover, the as-built samples possess tensile residual stress even fabricated with optimized parameters.

Heat treatment is essential to minimize the residual stress in AM parts [2]. Kim et al. [3] observed that heat treatment of IN718 alloy at a low-temperature range between $100^{\circ} \mathrm{C}$ to $400^{\circ} \mathrm{C}$ does not alter the residual stress nature. The residual stress magnitude was found to be $70 \mathrm{MPa}$ in stress relieved conditions and150MPa in as-built conditions. Also, found that no phase changes occur at temperatures below $400^{\circ}$ C. Karabulut et al. [8] and Rahimi et al. [28] found that the heat treatment at $620^{\circ} \mathrm{C}$ and $720^{\circ} \mathrm{C}$ partially reduce the residual stress by precipitating $\gamma^{\prime \prime}$ and $\gamma^{\prime}$ phases by stopping dislocations. The strengthening phase $\gamma$ " start to precipitate at $600^{\circ} \mathrm{C}$ and above $650^{\circ} \mathrm{C}$ the $\gamma$ " phases started decomposes to stable $\delta$ phase [1,4]. Diepold et al. [13] found that solution treatment at $930^{\circ} \mathrm{C}$ and $954^{\circ} \mathrm{C}$ promote the segregation of detrimental $\delta$ phases which minimizes the volume fraction of $\gamma^{\prime}$ and $\gamma^{\prime \prime}$ phases. Qi et al. [29] reported that solution heat treatment at $980^{\circ} \mathrm{C}$ is not completely dissolving the laves phase. A high-temperature heat treatment process is necessary to dissolve the $\delta$ and Laves phases and allow homogeneous grain growth by recrystallization. It also enables the thermal diffusion process and resulted in recrystallization by releasing the internal energy compared to the low-temperature heat treatment. 
In order to reduce the residual stress with a favorable microstructure, the hightemperature heat treatment process is necessary. The present work aims to investigate the effect of high-temperature heat treatment on phase transformation, residual stress distribution, and microhardness evolution of L-PBF fabricated IN718 alloy samples.

\section{Experimental Procedure}

\subsection{Materials and fabrication}

The chemical composition of IN718 alloy measured using SPECTRO xSORT handheld XRF elemental spectrometer is given in Table.1. The measured alloying elements were compared with the AMS5662 standard and the weight percentages of alloying elements were found to be within the allowable range. The SEM images of IN718 alloy powder particles used for fabrication are shown in Fig.1(a) and (b). The particles were produced using the gas atomization process. The particle exhibits spherical shape and distributed evenly with particle size varying between $24-45 \mu \mathrm{m}$. The uniformability in the shape of the powder particles gives good flowability during stacking of powder bed.

The CAD model was generated with dimensions 50 × 50 × $6 \mathrm{~mm}$ using solid works software and exported to pre-processing software Materialize Magics in STL file format to define the process parameters. The fabrication was made using an EOS M280 machine uses YB-fibre (Ytterbium) laser source to melt the powder particles. At the time of fabrication, the build chamber was maintained with an inert environment to minimize the oxygen concentration of less than $0.1 \%$ by supplying the argon gas to prevent the samples from oxidation and other atmospheric contamination. The process parameters used for fabricating the samples are given in Table.2.The built direction was kept in a horizontal orientation to minimize the interlayer defects compared to vertically built samples. The total number of layers used to build a complete specimen is 150 with each layer having a thickness of $40 \mu \mathrm{m}$. The $67^{\circ}$ rotated raster scanning strategy between successive layers was used for fabrication to 
avoid the accumulation of residual stress in a particular direction. The scanning pattern used for fabrication in this work is schematically represented in Fig.1(c).

\subsection{High-temperature heat treatment}

A post-heat-treatment process at high temperature was used to alter the presence of thermally induced residual stresses in L-PBF fabricated IN718 samples. The heat treatment was carried out in a box furnace as per the AMS 5664 standard. The phase transformation with respect to the thermal cycle is schematically represented in Fig.2. The heat treatment cycle follows a solution annealing at $1065^{\circ} \mathrm{C}$ for 1 hour 30 minutes followed by furnace cooling [31].

\subsection{Material characterization}

The samples were prepared for microstructural analyses to explore the effect of microstructures on resulting residual stress. The samples were cut into small pieces and polished with different grades of emery sheets from hand to disk polish in a sequential manner. To reveal the grain structure the samples were undergone a chemical etching process after polishing using kallings reagent for 2-3 seconds. The etchant has a composition of $5 \mathrm{~g}$ of $\mathrm{CuCl}_{2}+100 \mathrm{ml}$ of $\mathrm{HCl}+100 \mathrm{ml}$ of ethanol. Carl Zeiss optical microscope was used to capture the microstructural images at low magnifications. Further, the Field Emission- Scanning Electron Microscope (FE-SEM) Thermo Fisher FEI QUANTA 250 FEG was used to take the high magnification microstructural images. The distribution of elements and the phases present in both as-built and heat-treated samples were identified with the help of an EnergyDispersive spectrometer (EDS) and Bruker D8 X-ray diffractometer (XRD). The X-ray was energized by a $\mathrm{Cu}-\mathrm{K} \alpha \mathrm{X}$-ray source with a wavelength of $1.54 \AA$ and analyzed within the $2 \theta$ range between $0^{\circ}$ to $100^{\circ}$ with a scan speed of $0.5^{\circ} /$ minute. 


\subsection{Microhardness analysis}

The microhardness measurement was performed on both as-built and stress relived IN718 samples. The microhardness test was carried out along the top surface and crosssection by using Matsuzawa (MMT-x), Vickers hardness tester at different locations. The indentations points were located at 30 different positions with equal intervals under the load of $100 \mathrm{gf}$ for a dwell time of $10 \mathrm{Sec}$.

\subsection{Residual stress measurement}

The residual stress measurement was done on both as-built and stress relieved samples using the Pulstec $\mu$-X360 portable stress analyzer. It works based on the $\cos \alpha$ method and the residual stress measurement setup used in the present work is shown in Fig.3. The diffraction plane for FCC structured nickel alloy is set to be $\{311\}$. The incident angle of the X-ray was set to be $30^{\circ}$. The voltage and current used for operating the X-ray tube are 30 $\mathrm{kV}$ and $1.0 \mathrm{~mA}$ which help to produce an X-ray at a wavelength of $2.29093 \AA$. The diameter of the X-ray beam spot is $2 \mathrm{~mm}$. The distance between the detector and sample for all the measured points was kept constantly at $39 \mathrm{~mm}$ and the penetration depth of the X-ray was $8 \mu \mathrm{m}$ for IN718 alloy [6]. The residual stresses were measured at eight different points on the top and lateral side surfaces by varying the orientations of the samples with respect to the incident direction of the X-ray.

The X-ray diffraction method works on the principle of Bragg's law of diffraction. The incident X-ray satisfies Bragg's law shown in equation (1).

$$
n \lambda=2 d \sin \theta
$$

Where $\theta=$ diffraction angle, $d=$ lattice spacing, and $\lambda=$ wavelength of the $\mathrm{X}$-ray. The residual stress is calculated by comparing the $\mathrm{d}_{0}$ lattice spacing between stress-free and 
stressed samples. The lattice plane spacing will be equal to $d_{0}$ for the lattice plane orientation which is parallel to the surface. The diffracted X-rays create a symmetrical cone shape with incident X-ray in 3D space. In general, the cone shape captured using a detector gives a perfect round-shaped Debye-ring for the stress-free samples. When the material has residual stress it affects the diffracted X-ray with different diffraction angle $2 \theta$ which affect the symmetry of the round-shaped Debye-ring and resulted in the Debye-ring shift toward outwards from the original centre position. The schematic view of Debye ring formation is represented in Fig.4. In this method, the residual stress can be calculated from the following equation $(2)[32,33]$.

$$
\sigma_{x}=\frac{E}{1+\gamma} \frac{1}{\sin 2 \eta \sin 2 \varphi_{0}} \frac{\partial \varepsilon_{\alpha}}{\partial \cos \alpha}
$$

Where, $\mathrm{E}=$ Young's modulus, $\gamma=$ Poisson's ratio. The residual stress is the function of the slope of $\cos \alpha$ corresponding strain $\varepsilon_{\alpha}$. The angle $\alpha$ in the Debye ring can be calculated by the equation (3) and the strain can be calculated from the following equation (4) [32].

$$
\begin{gathered}
\varepsilon_{\alpha}=a_{0} \cos \alpha+b_{1} \sin \alpha+a_{2} \cos 2 \alpha+b_{2} \sin 2 \alpha \\
\varepsilon_{a 1}=\frac{1}{2}\left[\left(\varepsilon_{\alpha}-\varepsilon_{\pi+\alpha}\right)+\left(\varepsilon_{-\alpha}-\varepsilon_{\pi-\alpha}\right)\right]
\end{gathered}
$$

Where $\alpha, \pi+\alpha,-\alpha, \pi-\alpha$ is four angles on Debye ring. The residual stress can be calculated by analyzing the function between $\cos \alpha$ and $\varepsilon_{\mathrm{a} 1}$ which is determined by the angles on the Debye ring. 


\section{Result and Discussion}

\subsection{As-built microstructure of IN718 alloy}

The microstructure of the as-built IN718 alloy consists of melt pool boundaries in the form of an arc-shaped structure which is induced by the Gaussian distribution of laser energy along the build direction. The temperature gradient is more in build direction which allows the melt pool to solidify from bottom to top along the heat flow direction. This directional solidification of melt pools helps the growth of columnar grains and dendrites. During cooling after solidification, the dendritic grain growth starts to evolve along the build direction. At the time of melting, the heat energy is transferred to previously solidified layers toward the build platform. The columnar grain growth and dendrites crossing across multilayers and several melt pool boundaries are shown in Fig.5(a). Some of the columnar grains experience deviated angular grain growth with respect to build direction. It was mainly because of differences in heat flow within the melt pool and thermal gradient between scanning and build direction.

The major alloying elements like $\mathrm{Nb}, \mathrm{Mo}$, and $\mathrm{C}$ influence the microsegregation at the time of repeated heating and cooling cycles. The SEM images of as-built L-PBF IN718 show very fine dendritic structures and coarser columnar $\gamma$ grains along the build direction which is shown in Fig.5(b). In addition, small irregular disc-shaped intermetallic brittle laves phases $\left((\mathrm{Ni}, \mathrm{Cr}, \mathrm{Fe})_{2}(\mathrm{Nb}, \mathrm{Mo}, \mathrm{Ti})\right)$ were present in the interdendritic regions as shown in Fig.5(c). The $\mathrm{Nb}$-rich laves phases were precipitated as a result of microsegregation of $\mathrm{Nb}$ from the basic $\gamma$ matrix due to non-equilibrium solidification holds down the precipitations of strengthening $\gamma^{\prime}$ and $\gamma^{\prime \prime}$ phases. The presence of laves phases in the $\gamma$ matrix was confirmed with the help of EDS results shown in Fig.5(d). 


\subsection{Surface morphology of As-built sample}

The solidified laser weld track generated on the powder bed is clearly visible towards the scanning direction on the top surface of as-built samples is shown in Fig.6(a). It was found that the weld tracks are not straight throughout the scan length and the uneven width of the track gives a waviness as shown in Fig.6(b). Also, the top layer which was fabricated at last consists of the unmelted powder particles in between the adjacent laser weld tracks as shown in Fig.6(c). It is mainly because of the thermocapillary convection flow of the melt pool. The capillary flow happens due to the temperature difference between the head and tail of the melt pool. The variation of volumetric energy density within the spot diameter causes an imbalance in surface tension along the scanning path. This action attracts the powder particles towards the melt pool which tends to partially fuse the particles and stick on the melt pool at the time of solidification. However, this problem will arise only on the final layer due to the absence of remelting. Further, if the hatch spacing is more than the laser spot diameter, then there will be a chance of increasing the amount of partially melted powder particles.

\subsection{Heat-treated microstructure of IN718 alloy}

The heat-treated microstructure of IN718 alloy shows an absence of melt pool boundaries, columnar dendritic structures, and columnar grain boundaries in Fig. 7(a) and (b). At the time of heat treatment, the sample undergone recrystallization resulted in more homogeneous finer equiaxed grains. The laves phases present in the interdendritic regions of the as-built microstructure was completely eliminated and provoked the precipitation of strengthening $\gamma^{\prime}$ and $\gamma^{\prime}$ ' phases in the grain interiors as shown in Fig.7 (c). Based on the TTT diagram [34] of IN718 alloy, almost all the lave phases are dissolved around $1060^{\circ} \mathrm{C}$. It also promotes the formation of annealing twins and recrystallized grains in the resultant microstructure. The presence of annealing twins in the recrystallized regions and precipitation 
of metal carbides $((\mathrm{Nb}, \mathrm{Ti}) \mathrm{C})$ in both grain interiors as well as in the grain boundaries are shown in Fig.7 (d) and (e). The annealing twins could contribute to strengthening the material with large-angle boundaries, by blocking the dislocation motion of grains [35]. The presence of metal carbides and strengthening phases are confirmed with the help of the EDS result which is shown in Fig.7 (f). As compared to as-built samples the $\sim \mathrm{Wt} \%$ of $\mathrm{Nb}$ is increased in the basic $\gamma$ matrix after heat treatment. It causes mainly due to $\mathrm{Nb}$-rich strengthening $\gamma^{\prime}$ and $\gamma$ " phases were precipitated more in the grain interiors. And also the metal carbides were formed due to the reaction of carbon atoms with refractory elements of $\mathrm{Nb}$, Mo, and $\mathrm{Ti}$ by dissolving laves phases in the $\gamma$ matrix. Further, carbides were formed due to higher solubility rate of $\mathrm{Nb}$ at the time of cooling.

\subsection{Residual stress distribution}

The distribution of surface residual stresses in as-built and stress relieved samples along the side surface and the top surface of the samples are shown in Table.3 (a) \& (b). The residual stress magnitudes are tensile in nature on the top surface of as-built samples. The magnitude of residual stress varied between $76 \mathrm{MPa}$ to $149 \mathrm{MPa}$ in the center region and 410 $\mathrm{MPa}$ to $625 \mathrm{MPa}$ in the corners. The average magnitude of residual stress is $77 \%$ higher in the corners as compared to the mid regions of the samples. It is mainly because of high thermal gradient developed between the powder bed and solidified layers. At the time of melting, the melt pool is surrounded by low thermal conductivity powder particles on one side. Because of lesser thermal conductivity, the melt pool heat was hard to transmit to the surrounding powder as compared to solidified layers. It develops high thermal gradients and resulted in higher residual stress in the corners. In addition, the material expansion and shrinkage are not restricted to the same level in the corners as compared to the center. 
Further, the magnitude of residual stress varies between $406 \mathrm{MPa}$ to $490 \mathrm{MPa}$ (along build direction) and $-13 \mathrm{MPa}$ to $-60 \mathrm{MPa}$ (along scanning direction) with $\mathrm{YZ}$ and $\mathrm{XY}$ orientation on the side surface in as-built samples. The residual stress magnitudes were found to be tensile in nature along the build direction and compressive in nature along the scanning direction. The average magnitude of surface residual stresses was found to be $35.5 \%$ more in the top surface as compared to the side surface. It happens due to remelting of solidified layers causes a higher temperature difference between the layers. In addition, the recently built layer tries to shrink which is usually restricted by the subsequent bottom layers till attains its equilibrium. It leads to the development of tensile residual stresses between the layers along the build direction. The compressive stress was found in the XY direction mainly due to minimum overlapping between laser tracks. The overlapping of laser tracks is prevented by a rotating scan strategy. The residual stress formation mechanism in the powder bed fusion process is schematically represented in Fig.8.

After heat treatment, the surface tensile residual stress in as-built samples was relieved and converted to compressive residual stresses in both top and side surfaces. The magnitudes of surface compressive residual stress are varied between $-255 \mathrm{MPa}$ to $-338 \mathrm{MPa}$ in the center region and $-244 \mathrm{MPa}$ to $-375 \mathrm{MPa}$ in the corners on the top surface of the samples. Further, the residual stress magnitude was found to be varied between $-320 \mathrm{MPa}$ to $345 \mathrm{MPa}$ along with $\mathrm{XY}$ orientation and $-129 \mathrm{MPa}$ to $-253 \mathrm{MPa}$ along the $\mathrm{YZ}$ direction in the lateral side surface. At high-temperature stress relieving heat treatment, the atomic diffusion increases which means the atoms present in the high-stress regions migrate to low-stress regions till attain their equilibrium condition is the major reason for the residual stress conversion. By the dislocation movement of atoms, the stresses present in the grain interiors were altered considerably and resulted in complete recrystallization, homogenization, and dissolution of brittle lave phases with precipitation of more strengthening phases. Further, the 
formation of the BCT lattice after heat treatment requires higher volume than the basic FCC lattice in as-built samples which tends to develop compressive residual stresses [36]. The geometry variation of Debye ring was observed due to change in the interplanar spacing which alters the diffracted angle [37].

The variation in residual stress between point to point within the top and lateral side surfaces in the as-built sample is mainly because the highly localized action of a laser beam causes a high thermal gradient resulting in uneven distribution of grain structures with dendrites. The stress relived samples undergo recrystallization and homogenization with precipitation of metal carbides with more strengthening phases. After recrystallization, the residual stress magnitude was found to be distributed evenly as compared to as-built conditions.

The FWHM values tend to change with respect to residual stress magnitude when simultaneous changes are noted in microstructure after heat treatment. Heat treatment induces grain refinement in the microstructure which affects the crystallite sizes and alters the residual stress magnitude. The Debey-Scherrer equation was used to calculate the FWHM values shown in equation (5) [38].

$$
F W H M=\frac{K \lambda}{L \operatorname{Cos} \theta}
$$

Where, $\mathrm{K}=$ shape constant $(\sim 0.89-1.39), \mathrm{L}=$ particle size, and $\lambda=$ Wavelength. From this observation, it was found that stress-relieving heat treatment at $1065^{\circ} \mathrm{C}$ for 1.5 hours effectively converts the tensile surface residual stress to compressive residual stresses with a homogeneous distribution of residual stresses by achieving a favorable microstructure. Marchese et al. [9] have attempted a similar kind of study and revealed that high-temperature annealing effectively reduces the residual stress magnitude with an increase in hardness as 
compared to low-temperature heat treatment. In addition complete dissolution of dendritic structure with the presence of intergranular metal carbides.

\subsection{XRD analysis}

The XRD peaks identified on powder, as-built, and heat-treated samples are shown in Fig.9. It was found that the basic $\gamma$ phase was detected in all three conditions. In addition, strengthening phases such as $\gamma^{\prime}$ and $\gamma^{\prime}$, phases were identified. Heat treatment at hightemperature causes recrystallization led to the precipitation of new phases, and it was found through new peaks in the heat-treated XRD pattern. Existing literature shows, the phases expected to present in the XRD pattern of L-PBF fabricated IN718 is $\gamma$ (Ni-Cr-Fe), $\gamma^{\prime}$ $\left(\mathrm{Ni}_{3} \mathrm{Nb}\right), \gamma^{\prime}{ }^{\prime}\left(\mathrm{Ni}_{3}(\mathrm{Al}, \mathrm{Ti})\right)$, laves $\left((\mathrm{Ni}, \mathrm{Cr}, \mathrm{Fe})_{2},(\mathrm{Nb}, \mathrm{Mo}, \mathrm{Ti})\right)$ and $\mathrm{MC}((\mathrm{Nb}, \mathrm{Ti}) \mathrm{C})[30]$. Consistent with the literature the spectra overlap in (200) and (220) planes are observed mainly because of coherency and same crystal structure which resulted in difficulties in differentiating the $\gamma$ and $\gamma^{\prime}$ phases in all the samples of IN718 alloy [11]. The peaks for laves phases present in the interdendritic regions of as-built samples are not visible because of low volume fractions as compared to other phases. The crystallite size was calculated using Scherrer equation (6) and, observed that the dislocation density of heat-treated samples was more as compared to as-built samples. The dislocation density and microstrain were calculated with equation (7). The crystalline size was reduced in a heat-treated sample which confirms that the sample undergo complete recrystallization and resulted in finer grains. The characterization of IN718 alloy from XRD data is shown in Table.4. The miller indices hkl plane for the position of the corresponding peaks from the $2 \theta$ value can be calculated with the help of Bragg's law with the interplanar spacing equation shown in equations (1).

$$
\begin{aligned}
& D=\frac{K \lambda}{\beta \cos \theta} \\
& \delta=\frac{1}{D^{2}}
\end{aligned}
$$


Where, $\lambda=$ Wavelength of X-ray, $\mathrm{d}=$ interplanar spacing, $a=2 r / 2^{1 / 2}$, and $\mathrm{r}=$ atomic radius of $\mathrm{Ni}, \mathrm{k}=$ constant, $\delta=$ dislocation density, $\mathrm{D}=$ crystallite size, $\beta=\mathrm{FWHM}$ and $\varepsilon=$ micro strain.

\subsection{Microhardness}

The hardness values obtained along the building direction and the laser scanning direction of as-built and heat-treated samples are shown in Fig.10. The effect of phase transformation and the precipitation of strengthening phases are correlated to the measured hardness values. The average hardness values after stress relieving heat treatment were increased from $415 \mathrm{HV}_{0.1}$ to $518 \mathrm{HV}_{0.1}$ on the top surface which is $24.98 \%$ more than the average hardness of as-built samples. The average hardness value of the heat-treated sample along the build direction increased from $413 \mathrm{HV}_{0.1}$ to $501 \mathrm{HV}_{0.1}$, which is $21.30 \%$ more than the as-built sample. The differences in average hardness value are graphically represented in Fig.11. The increase in hardness is evident for the formation of strengthening $\gamma^{\prime}$ and $\gamma^{\prime \prime}$ phases. The waviness observed in the hardness plot was mainly because of the indentations points measured at different phases. Haung et al. [1] reported that the pinning of dislocations by releasing a larger quantity of $\mathrm{Nb}, \mathrm{Al}$, and $\mathrm{Ti}$ elements is the main reason for hardness improvement. Further, the presence of a few annealing twins and metal carbides helps to enhance the strength of the matrix [39]. The grain size has an inverse relation with the hardness.

\section{Conclusion}

The present work aims to investigate the effect of heat treatment at $1065^{\circ} \mathrm{C}$ on phase transformation, residual stress distribution, and microhardness of the L-PBF fabricated IN718 alloy. The following conclusions have been made based on the study. 
- The as-built microstructure of IN718 exhibits arc-shaped melt pool boundaries and finer dendrites with columnar grains along the build direction. In few locations, angular grain growth was observed. The brittle laves phases were also present in the interdendritic regions.

- The high-temperature heat treatment alters the microstructure by undergoing recrystallization and resulted in more homogeneous finer equiaxed grains with an absence of melt pool boundaries and laves phases. The Nb-rich strengthening $\gamma^{\prime}$ and $\gamma$ ' phases, and metal carbides $((\mathrm{Nb}, \mathrm{Ti}) \mathrm{C})$ were precipitated by dissolving laves phases in the basic $\gamma$ matrix. The annealing twins were also formed in the grain interiors. The XRD results confirmed the presence of secondary phases along with EDS results.

- The uneven heating and cooling of the L-PBF process resulted in the accumulation of residual stress in the samples. The residual stress magnitude on the top surface varies between $76 \mathrm{MPa}$ to $149 \mathrm{MPa}$ in the centre region with an average of $115 \mathrm{MPa}$. Moreover, the residual stress magnitude was found to vary between $410 \mathrm{MPa}$ to $625 \mathrm{MPa}$ with an average of $513 \mathrm{MPa}$ in the corners. It shows that the residual stress is $77 \%$ more in the corners. Further, the residual stress varied between $406 \mathrm{MPa}$ to $490 \mathrm{MPa}$ in build direction and $-13 \mathrm{MPa}$ to $-60 \mathrm{MPa}$ in a scanning direction. It shows the residual stress nature is tensile along the build direction and compressive along the scanning direction. In addition, the average residual stress magnitude on the top surface was found to be $503 \mathrm{MPa}$ and $324 \mathrm{MPa}$ on the side surface which is $35.5 \%$ lesser than the side surface. It was also found that the distribution of residual stress was not uniform in as-built samples.

- After heat treatment, the magnitudes of residual stress are varying between $-255 \mathrm{MPa}$ to $-338 \mathrm{MPa}$ in the center region and $-244 \mathrm{MPa}$ to $-375 \mathrm{MPa}$ in the corners. Further, 
the residual stress magnitude was found to vary between $-320 \mathrm{MPa}$ to $-345 \mathrm{MPa}$ along the scanning direction and $-129 \mathrm{MPa}$ to $-253 \mathrm{MPa}$ along the build direction. In addition, the average residual stress magnitude in the top surface is $-490 \mathrm{MPa}$ and the side surface is $-435 \mathrm{MPa}$. It shows that residual stress on the side surface is slightly higher than the top surface on heat-treated samples with compressive nature.

- The high-temperature heat treatment effectively alters the residual magnitude and its distribution by achieving a favorable microstructure. It also converts the uneven tensile residual stress to uniform compressive residual stress effectively.

- The average microhardness value increases from $414.6 \mathrm{HV}$ to $510.1 \mathrm{HV}$ after heat treatment which is a $23.03 \%$ increase in microhardness values. The precipitation of the strengthening phase along with twin boundaries helps to fragment the bigger grain boundaries to finer grain boundaries by stopping the dislocation motions.

\section{Declaration Statement}

The authors declare that this manuscript was not submitted to more than one journal for simultaneous consideration. Also, the submitted work is original and has not been published elsewhere in any form or language.

\section{Funding and Competing Interests}

The authors did not receive support from any organization for the submitted work. Also, the authors have no relevant financial or non-financial interests to disclose.

\section{Conflict of interest}

The authors declare no competing interests. 


\section{Author Contributions}

All authors contributed to the study conception and design. Material preparation, data collection and analysis were performed by V. Praveen Kumar. The first draft of the manuscript was written by V. Praveen Kumar and all authors commented on previous versions of the manuscript. All authors read and approved the final manuscript.

\section{Availability of data and materials}

Data sharing is not applicable to this article.

\section{Availability of Code}

Not Applicable

\section{Consent to participate and publish}

The authors declare that they participated in this paper willingly and the authors declare to consent to the publication of this paper.

\section{References}

[1] Huang W, Yang J, Yang H, et al (2019) Heat treatment of Inconel 718 produced by selective laser melting: Microstructure and mechanical properties. Mater Sci Eng A Struct Mater 750:98-107

[2] Teixeira Ó, Silva FJG, Atzeni E (2021) Residual stresses and heat treatments of Inconel 718 parts manufactured via metal laser beam powder bed fusion: an overview. Int J Adv Manuf Technol 113:3139-3162

[3] Kim SY, Luzin V, Sesso ML, et al (2020) The effect of low temperature range heat treatment on the residual stress of cold gas dynamic sprayed inconel 718 coatings via neutron diffraction. J Therm Spray Technol 29:1477-1497

[4] Mignanelli PM, Jones NG, Pickering EJ, et al (2017) Gamma-gamma primegamma double prime dual-superlattice superalloys. Scr Mater 136:136-140 
[5] Kumara C, Balachandramurthi AR, Goel S, et al (2020) Toward a better understanding of phase transformations in additive manufacturing of Alloy 718 . Materialia 13:100862

[6] Samuel. S C, Arivarasu., Prabhu R (2020) High temperature dry sliding wear behaviour of laser powder bed fused Inconel 718. Addit Manuf 34:101279

[7] Karimi P, Sadeghi E, Ålgårdh J, et al (2021) Columnar-to-equiaxed grain transition in powder bed fusion via mimicking casting solidification and promoting in situ recrystallization. Addit Manuf 46:102086

[8] Karabulut Y, Tascioglu E, Kaynak Y (2021) Heat treatment temperatureinduced microstructure, microhardness and wear resistance of Inconel 718 produced by selective laser melting additive manufacturing. Optik (Stuttg) 227:163907

[9] Marchese G, Atzeni E, Salmi A, Biamino S (2021) Microstructure and residual stress evolution of laser powder bed fused Inconel 718 under heat treatments. J Mater Eng Perform 30:565-574

[10] Mercelis P, Kruth J-P (2006) Residual stresses in selective laser sintering and selective laser melting. Rapid Prototyp J 12:254-265

[11] Jiang R, Mostafaei A, Pauza J, et al (2019) Varied heat treatments and properties of laser powder bed printed Inconel 718. Mater Sci Eng A Struct Mater 755:170-180

[12] Chen Y, Sun H, Li Z, et al (2020) Strategy of residual stress determination on selective laser melted Al alloy using XRD. Materials (Basel) 13:451

[13] Diepold B, Vorlaufer N, Neumeier S, et al (2020) Optimization of the heat treatment of additively manufactured Ni-base superalloy IN718. Int J Miner Metall Mater 27:640-648 
[14] Liu F, Lyu F, Liu F, et al (2020) Laves phase control of inconel 718 superalloy fabricated by laser direct energy deposition via $\delta$ aging and solution treatment. J Mater Res Technol 9:9753-9765

[15] Lesyk DA, Martinez S, Mordyuk BN, et al (2020) Post-processing of the Inconel 718 alloy parts fabricated by selective laser melting: Effects of mechanical surface treatments on surface topography, porosity, hardness and residual stress. Surf Coat Technol 381:125136

[16] Liu P, Sun S-Y, Xu S-B, et al (2018) Effect of solid solution + double ageing on microstructure and properties in the layer by layer of the Z-Y interface of inconel 718 alloys fabricated by SLM. Mater Res 21

[17] Wang X, Chou K (2019) The effects of stress relieving heat treatment on the microstructure and residual stress of Inconel 718 fabricated by laser metal powder bed fusion additive manufacturing process. J Manuf Process 48:154163

[18] Barros R, Silva FJG, Gouveia RM, et al (2019) Laser Powder Bed Fusion of inconel 718: Residual stress analysis before and after heat treatment. Metals (Basel) 9:1290

[19] Anush Raj B, Winowlin Jappes JT, Adam Khan M, et al (2020) Direct metal laser sintered (DMLS) process to develop Inconel 718 alloy for turbine engine components. Optik (Stuttg) 202:163735

[20] Goel S, Sittiho A, Charit I, et al (2019) Effect of post-treatments under hot isostatic pressure on microstructural characteristics of EBM-built Alloy 718. Addit Manuf 28:727-737

[21] Bartlett JL, Li X (2019) An overview of residual stresses in metal powder bed fusion. Addit Manuf 27:131-149 
[22] Lu Y, Wu S, Gan Y, et al (2015) Study on the microstructure, mechanical property and residual stress of SLM Inconel-718 alloy manufactured by differing island scanning strategy.Opt Laser Technol 75:197-206

[23] Kemerling B, Lippold JC, Fancher CM, Bunn J (2018) Residual stress evaluation of components produced via direct metal laser sintering. Weld World 62:663-674

[24] Mirkoohi E, Tran H-C, Lo Y-L, et al (2020) Analytical modeling of residual stress in laser powder bed fusion considering part's boundary condition. Crystals (Basel) 10:337

[25] Mugwagwa L, Dimitrov D, Matope S, Yadroitsev I (2018) Influence of process parameters on residual stress related distortions in selective laser melting. Procedia Manuf 21:92-99

[26] Ahmad B, van der Veen SO, Fitzpatrick ME, Guo H (2018) Residual stress evaluation in selective-laser-melting additively manufactured titanium (Ti-6Al$4 \mathrm{~V}$ ) and inconel 718 using the contour method and numerical simulation. Addit Manuf 22:571-582

[27] Yi JH, Kang JW, Wang TJ, et al (2019) Effect of laser energy density on the microstructure, mechanical properties, and deformation of Inconel 718 samples fabricated by selective laser melting. J Alloys Compd 786:481-488

[28] Rahimi S, King M, Dumont C (2017) Stress relaxation behaviour in IN718 nickel based superalloy during ageing heat treatments. Mater Sci Eng A Struct Mater 708:563-573

[29] Qi H, Azer M, Ritter A (2009) Studies of standard heat treatment effects on microstructure and mechanical properties of laser net shape manufactured INCONEL 718. Metall Mater Trans A 40:2410-2422 
[30] Kumar VP, Jebaraj AV (2021) Influence of double aging heat treatment on phase transformation and dimensional accuracy of inconel 718 alloy made through laser-based additive manufacturing. Trans Indian Inst Met 74:31033117

[31] AMS5664: Nickel Alloy, Solution Heat Treated, Precipitation Hardenable SAE International. In: Sae.org. ttps://www.sae.org/standards/content/ams5664/. Accessed 6 Dec 2021

[32] Ao S, Li C, Huang Y, Luo Z (2020) Determination of residual stress in resistance spot-welded joint by a novel X-ray diffraction. Measurement (Lond) $161: 107892$

[33] Zhu P, Gou G, Li Z, et al (2019) Study of residual stresses in A7N01 aluminum alloy with X-ray diffraction Debye ring analysis. Int J Mod Phys B 33:1940032

[34] Thompson R G, Dobbs J R, Mayo D E (1986) The Effect of Heat Treatment on Microfissuring in Alloy 718. Welding research supplement 299-304

[35] Tucho WM, Cuvillier P, Sjolyst-Kverneland A, Hansen V (2017) Microstructure and hardness studies of Inconel 718 manufactured by selective laser melting before and after solution heat treatment. Mater Sci Eng A Struct Mater 689:220-232

[36] Preußner J, Oeser S, Pfeiffer W, et al (2014) Microstructure and residual stresses of laser remelted surfaces of a hot work tool steel. Int J Mat Res ( Z Metallkd) 105:328-336

[37] Vinoth Jebaraj A, Sugavaneswaran M (2019) Influence of shot peening on residual stress distribution and corrosion resistance of additive manufactured stainless steel AISI 316L. Trans Indian Inst Met 72:1651-1653

[38] Tanaka K (2019) The $\cos \alpha$ method for X-ray residual stress measurement using 
two-dimensional detector. Mech Eng Rev 6:18-00378-18-00378

[39] Babamiri BB, Indeck J, Demeneghi G, et al (2020) Quantification of porosity and microstructure and their effect on quasi-static and dynamic behavior of additively manufactured Inconel 718. Addit Manuf 34:101380 


\section{Figures}
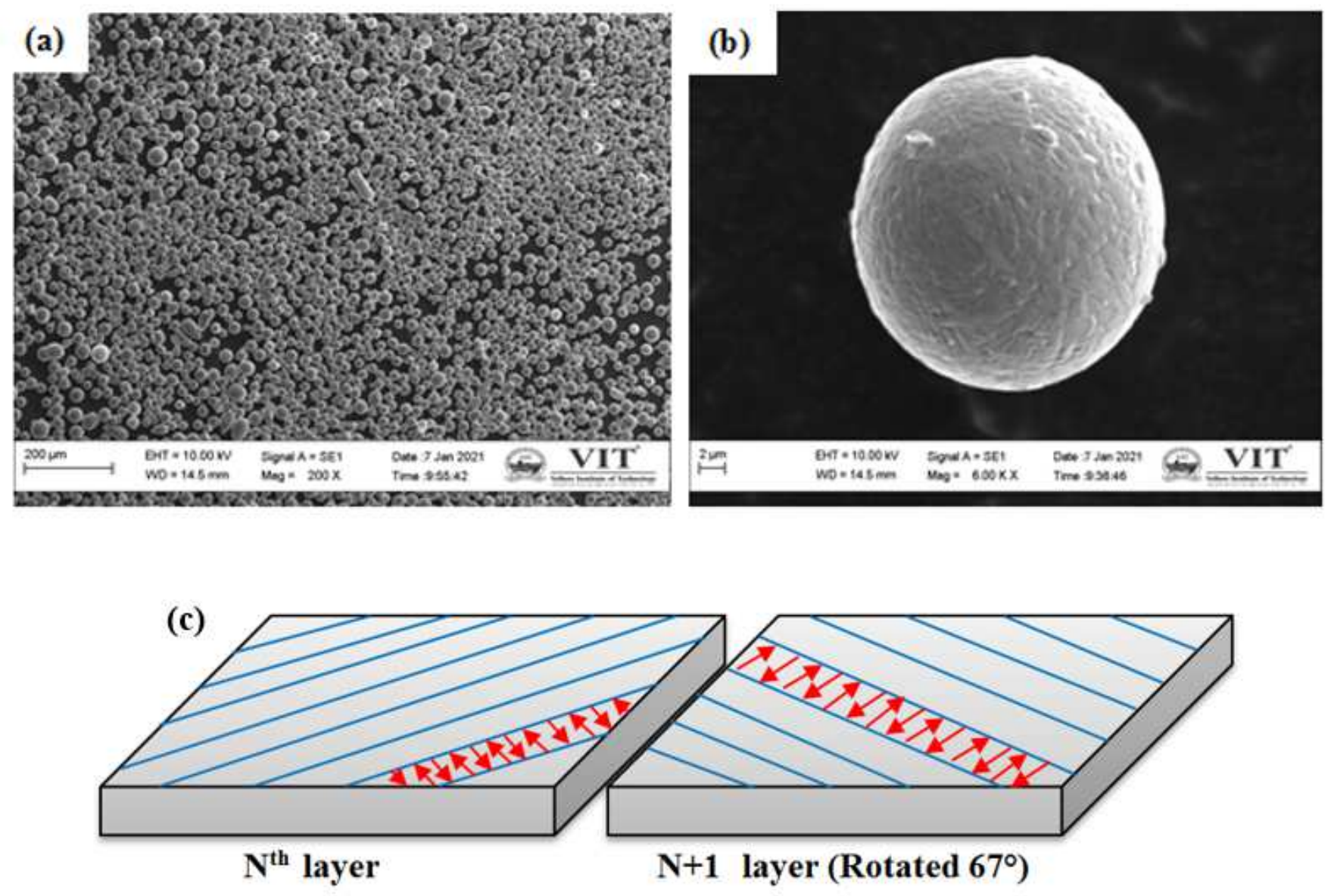

Figure 1

Morphology of powder particles: (a) Distribution of IN718 powder particles, (b) High magnification of powder particles and (c) Schematic of $67^{\circ}$ rotated raster scanning pattern. 


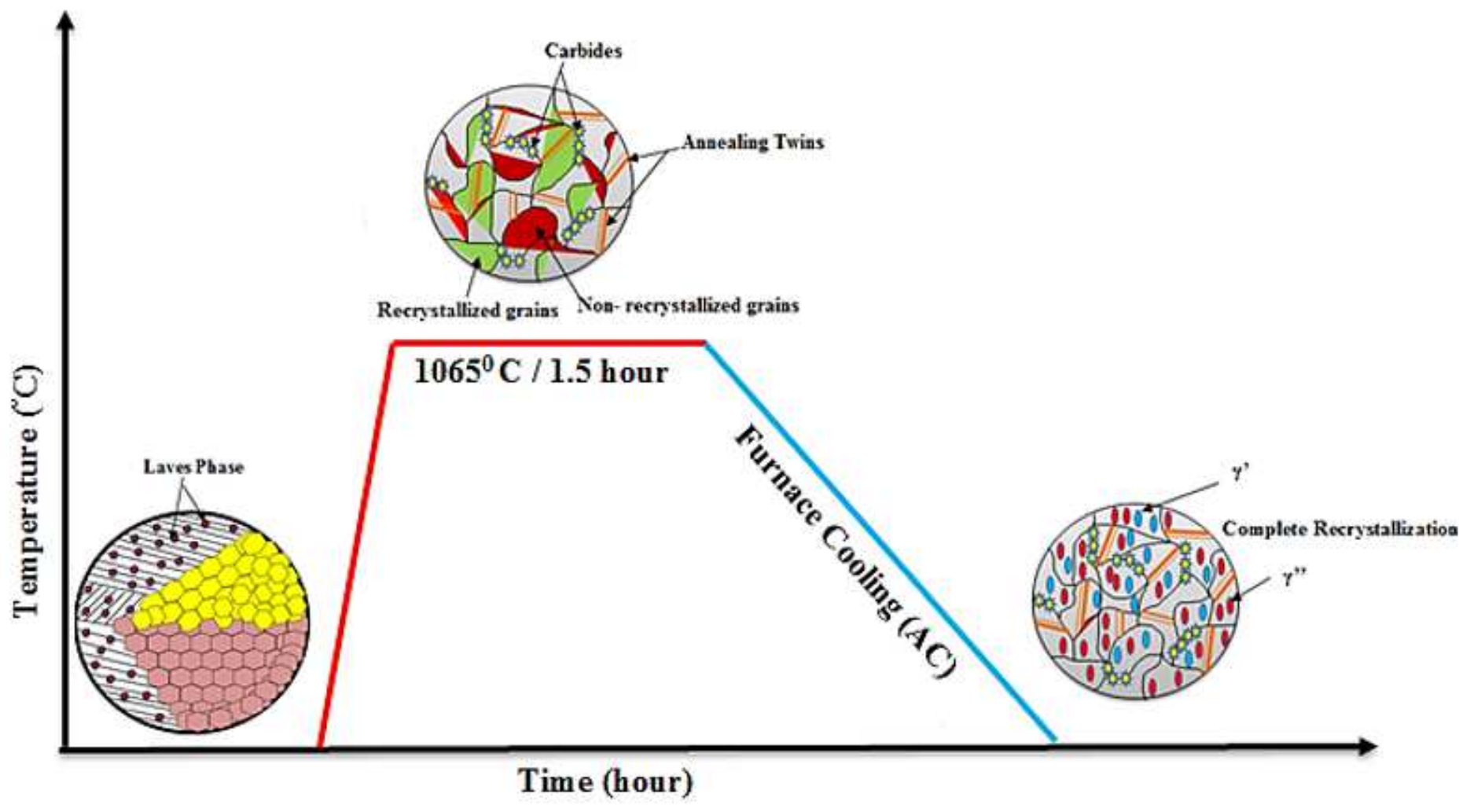

Figure 2

Schematic representation of microstructural phase changes with respect to temperature cycle

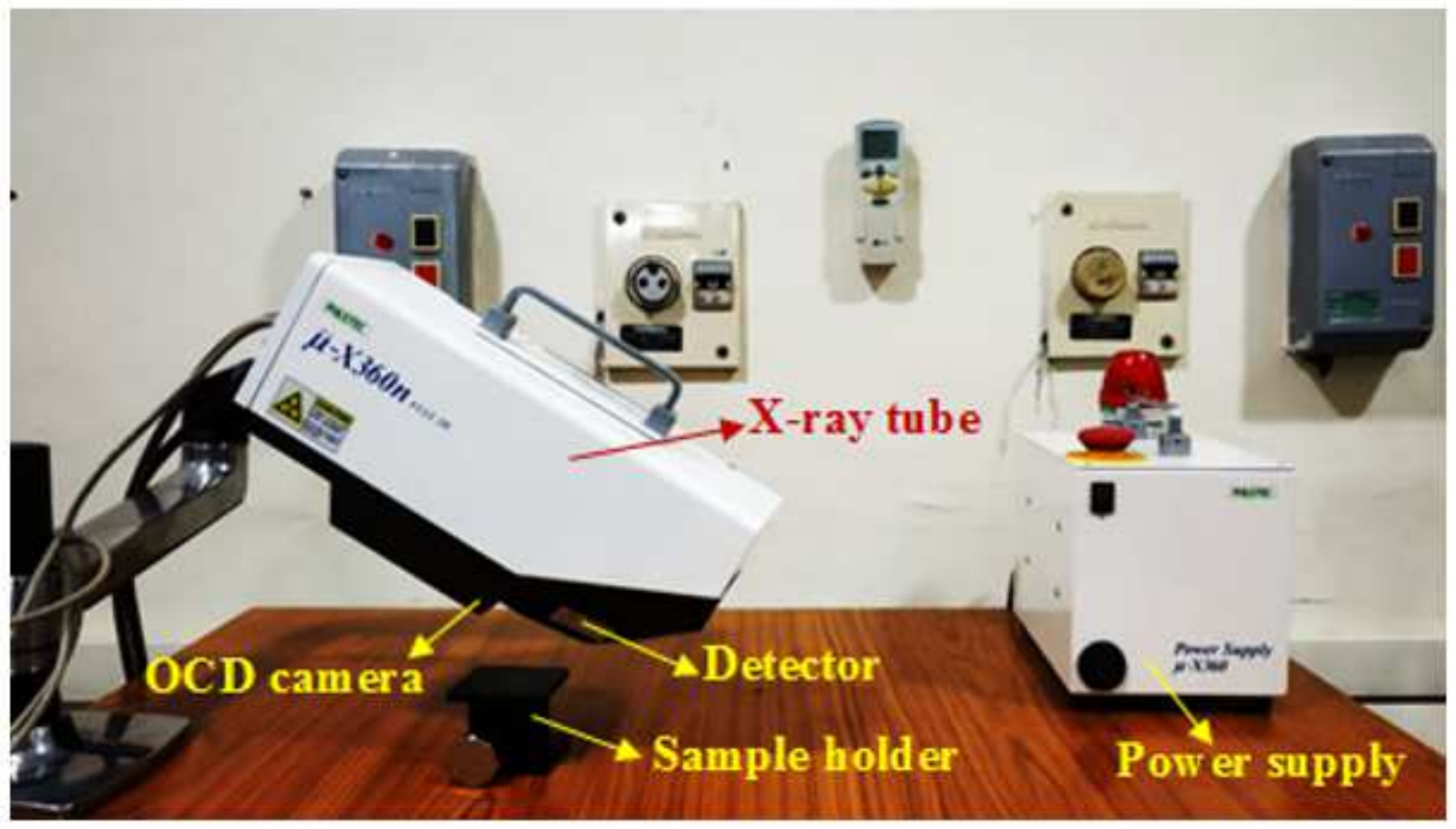

Figure 3 
$\mu$-X360 portable stress analyzer experimental setup

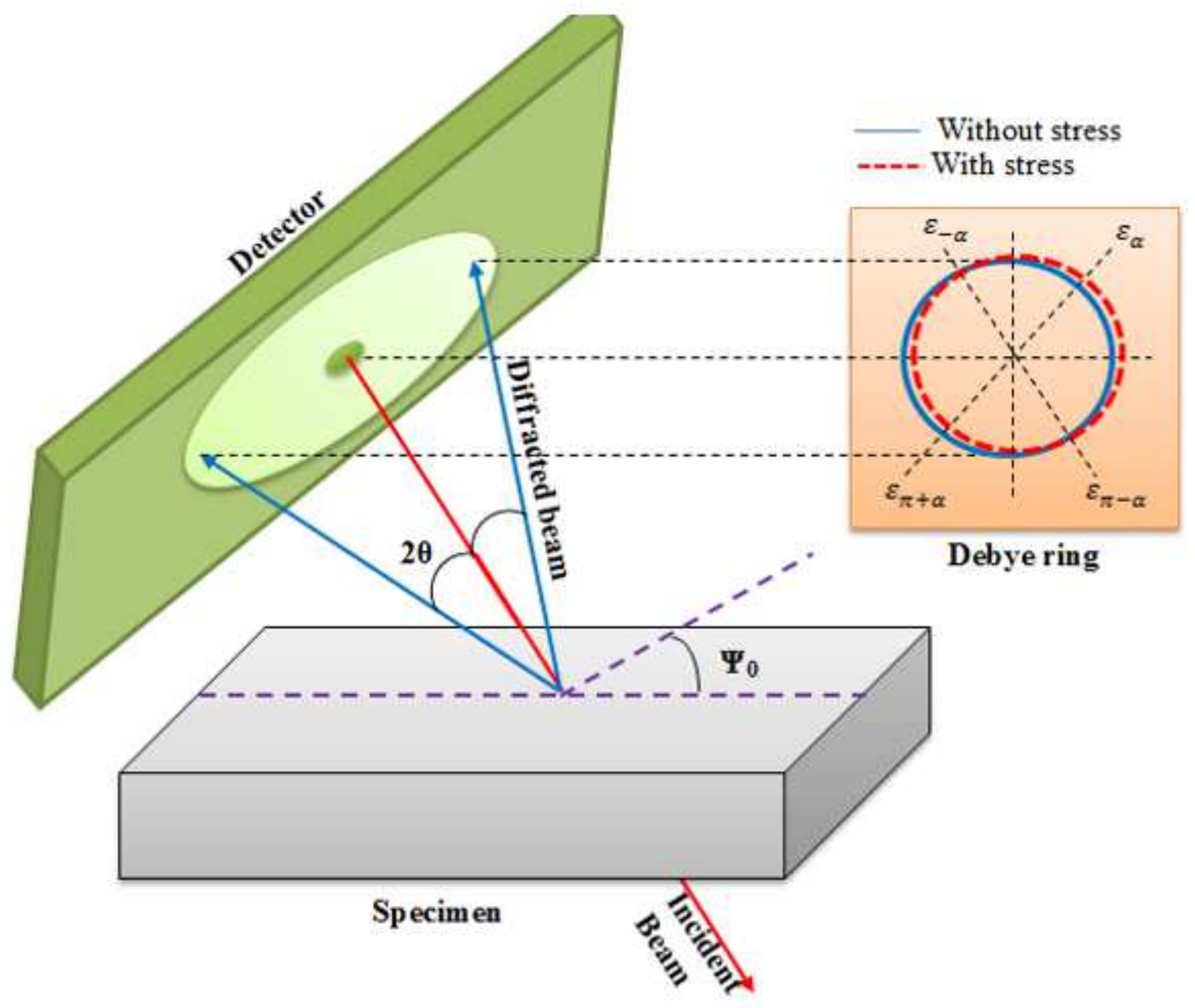

Figure 4

Schematic representation of Debye ring formation by using Cosa method

\section{Figure 5}

SEM images of as-built IN718 alloy. (a) Melt pool boundaries, (b) Dentrictic structure, (c) Laves phases present in the interdendritic region, (d) EDS results 


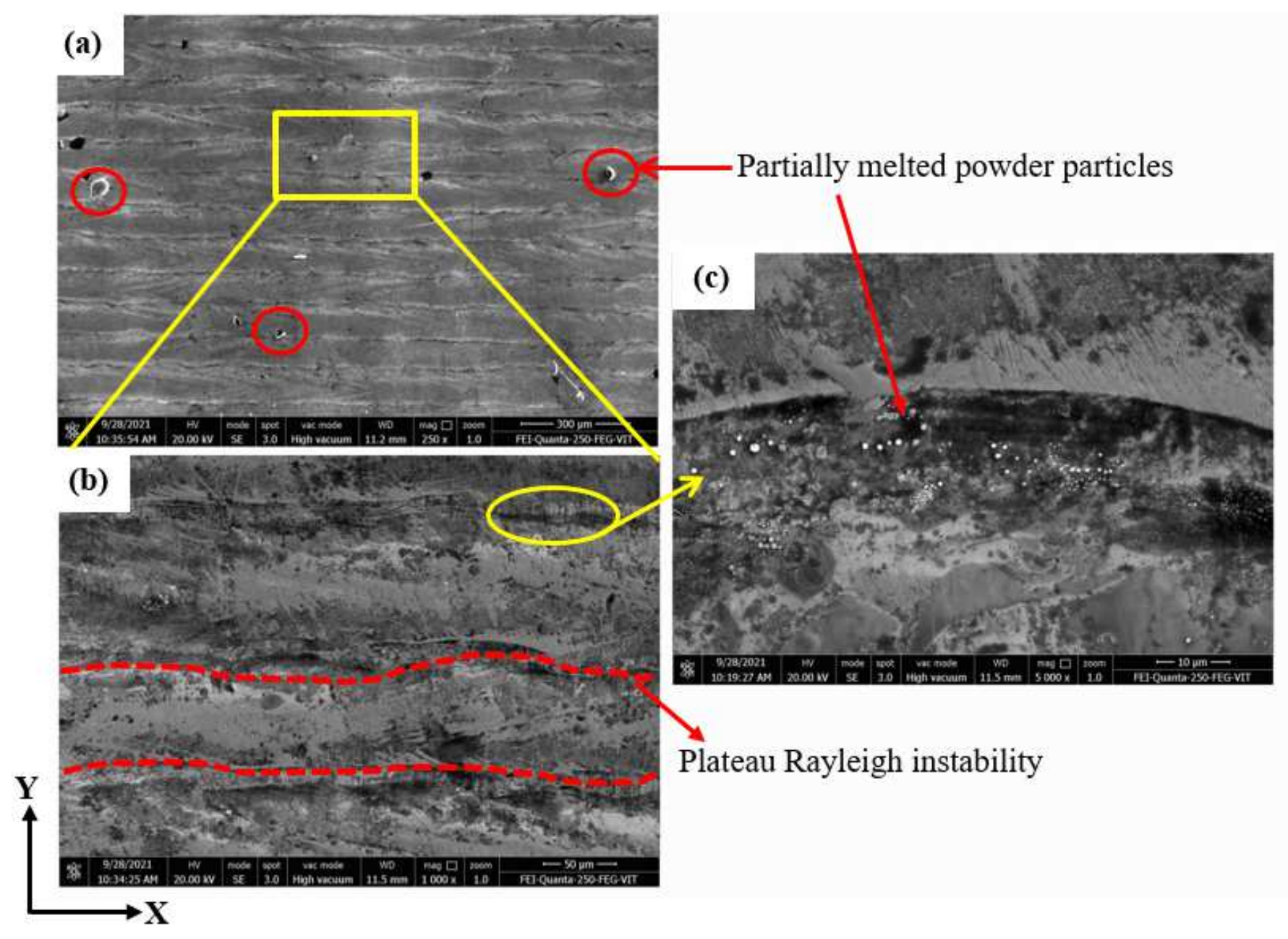

Figure 6

Surface morphology of DMLS fabricated IN718 alloy 

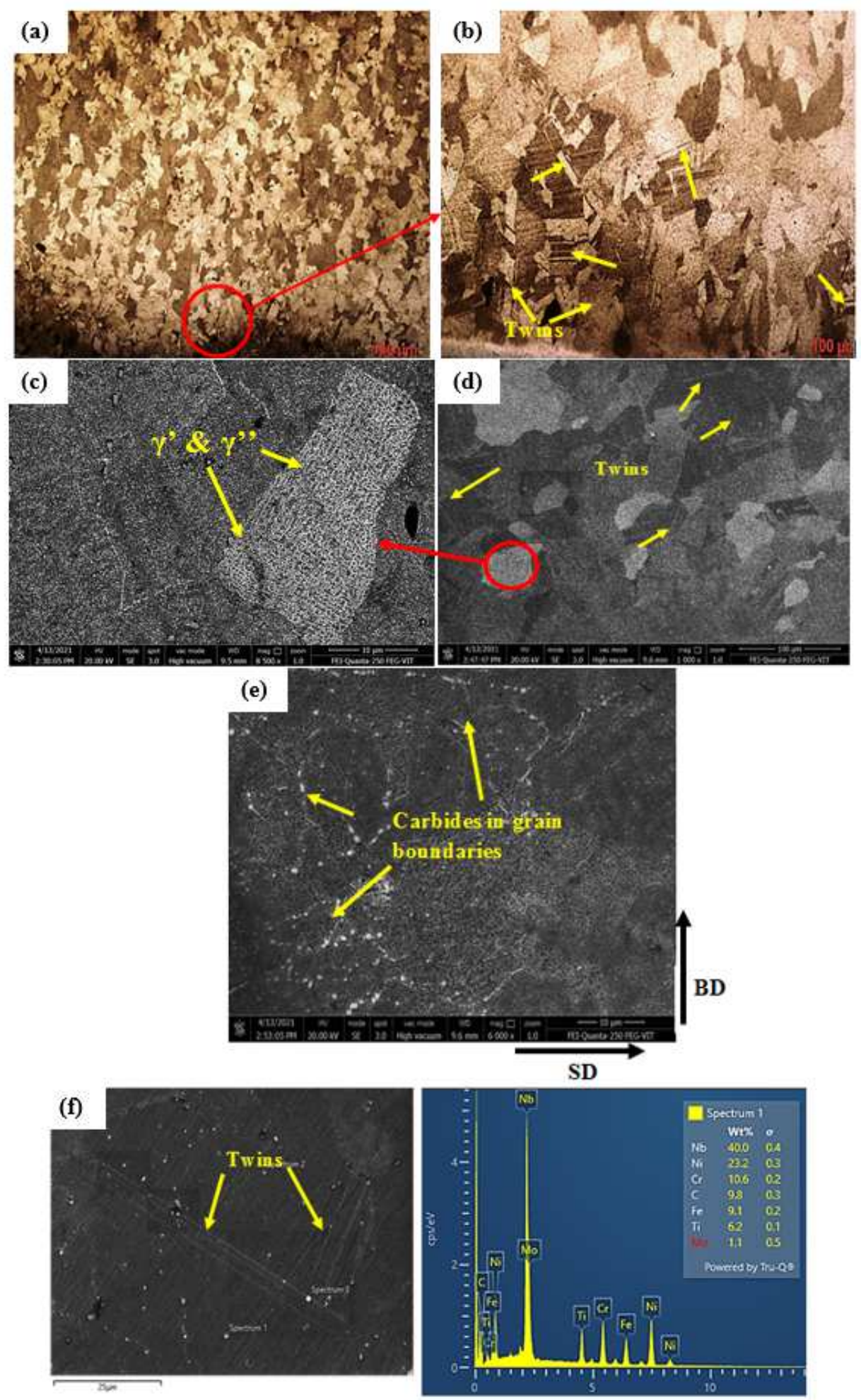

\section{Figure 7}

Microstructure of heat-treated IN718 alloy: (a) Lower magnification shows homogeneous equiaxed grain structures, (b) \& (d) Higher magnification shows annealing twins, (c) Strengthening phases, (e) Precipitation of carbides in grain boundaries, and (f) EDS results showing metal carbides 


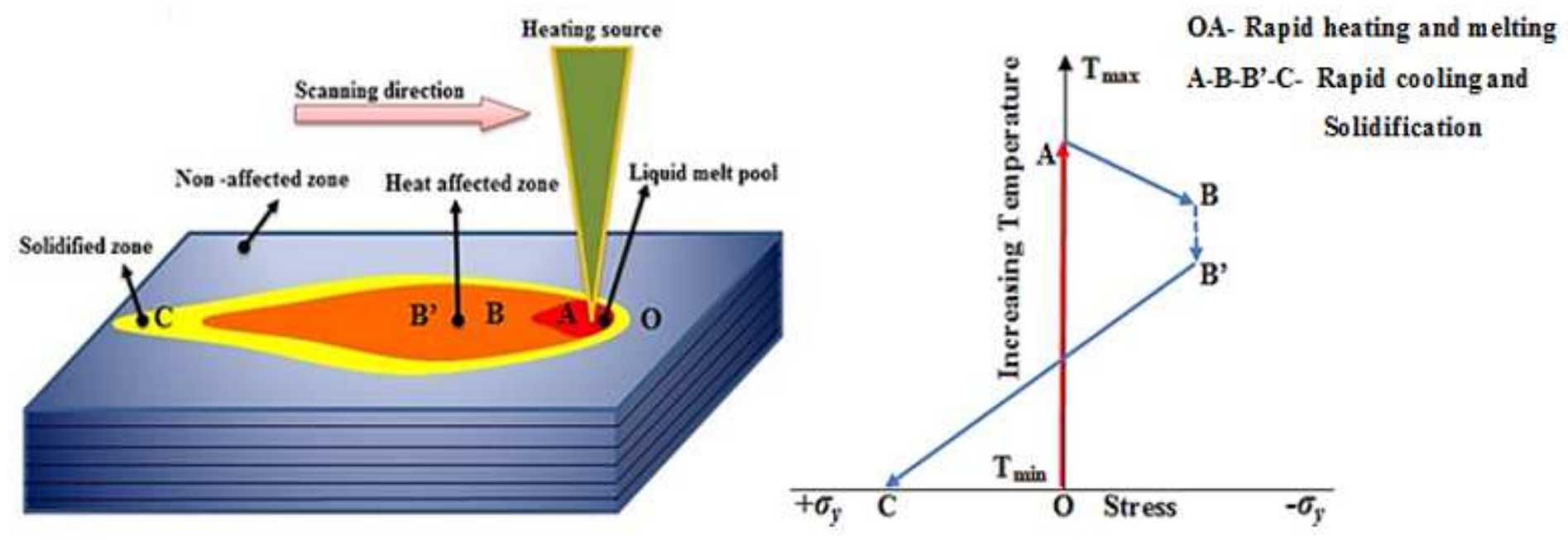

Figure 8

Schematic representation of residual stress formation in powder bed fusion

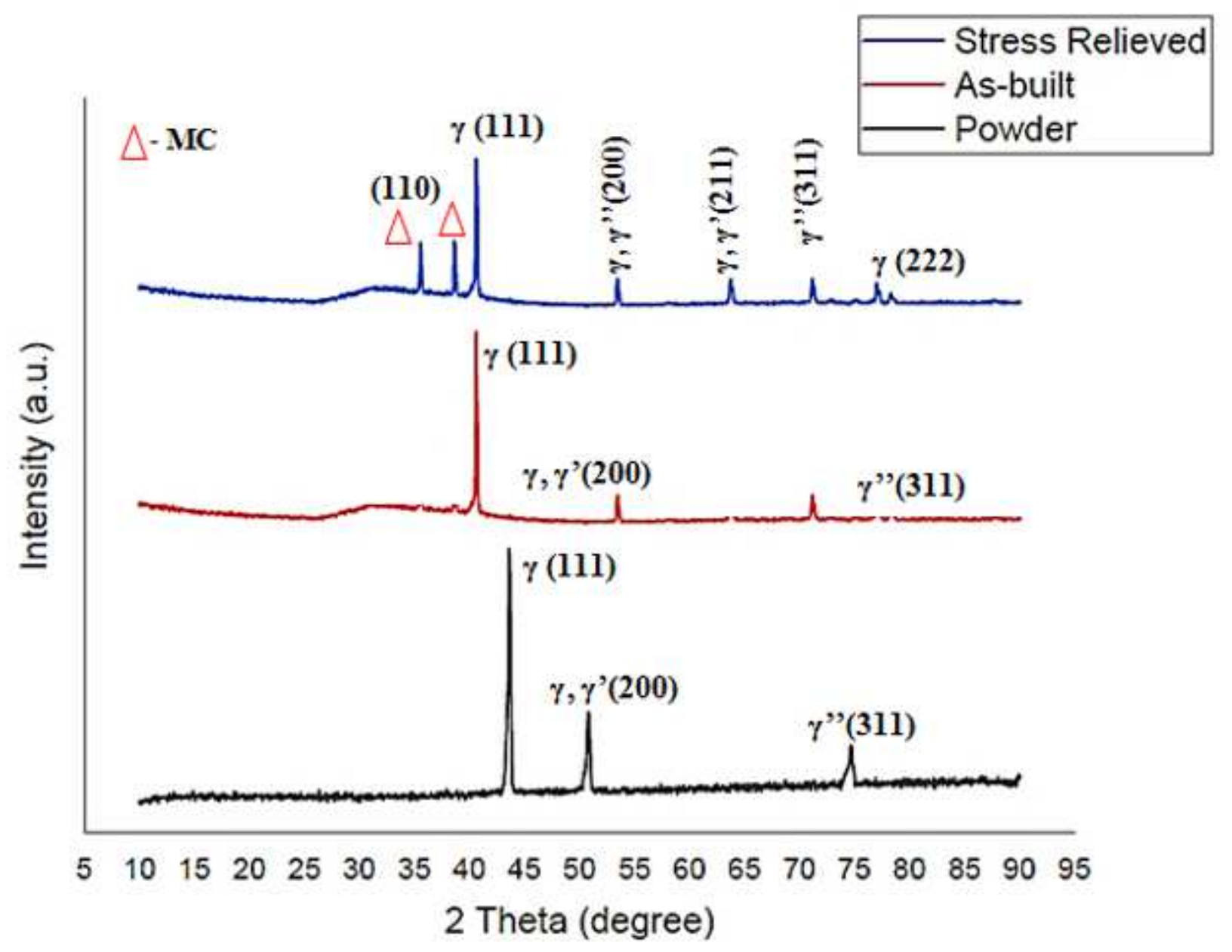

Figure 9 

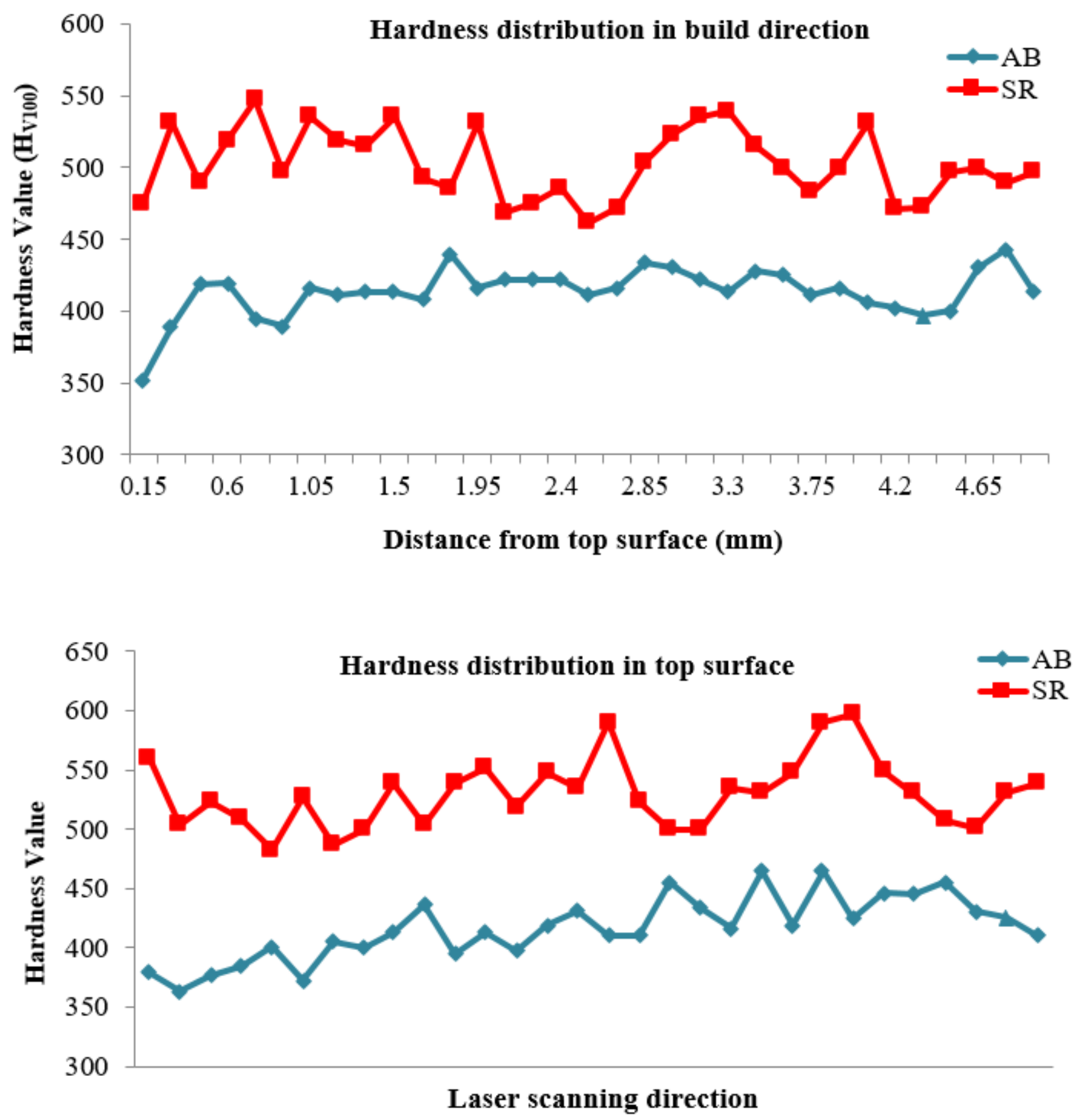

Figure 10

Hardness distribution in As-built and stress relieved IN718 samples 


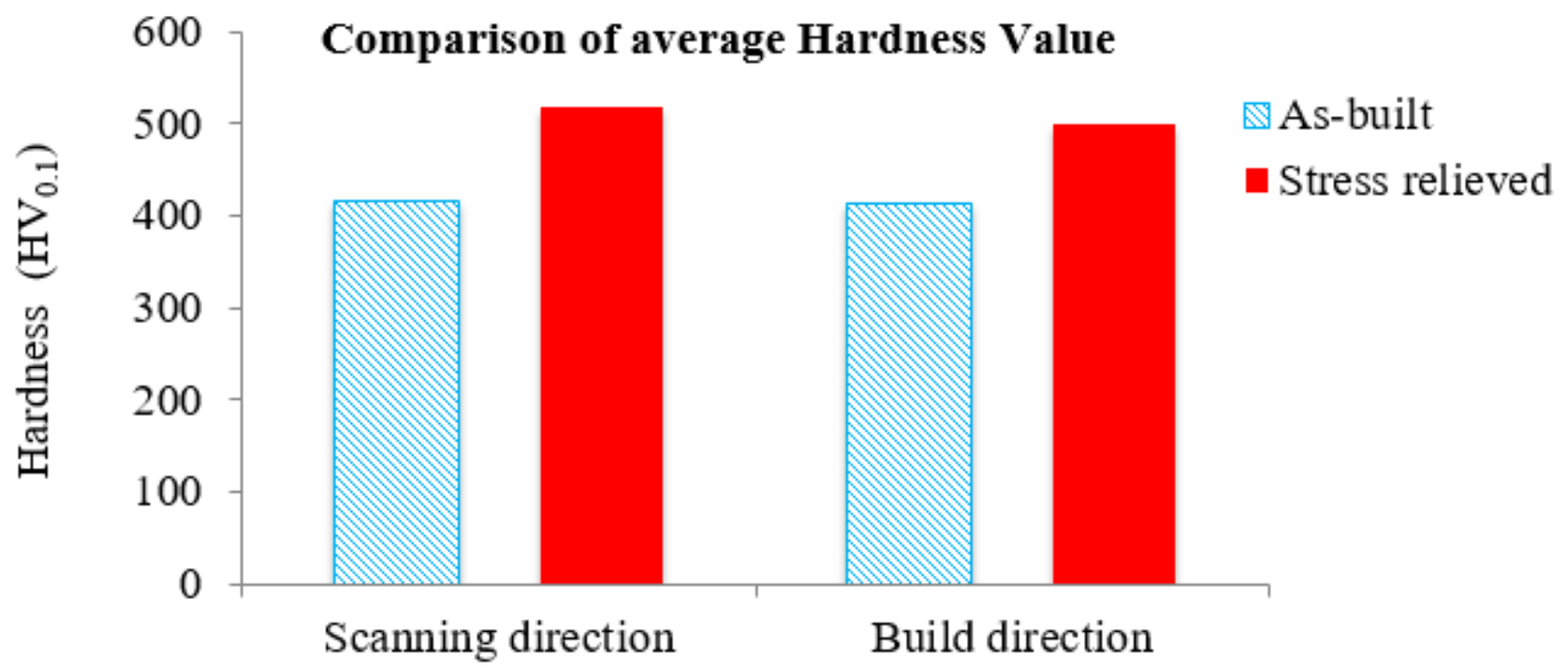

Figure 11

The average hardness of As-built and stress relieved IN718 alloy 